\title{
Reza Naseri, Mehrdad Malekzadeh, Ali Naseri. "Gūnespān: a late Iron Age site in the Median heartland"
}

\section{Rémy Boucharlat}

\section{(2) OpenEdition \\ 1 Journals}

\section{Édition électronique}

URL : http://journals.openedition.org/abstractairanica/46807

DOI : 10.4000/abstractairanica.46807

ISBN : 1961-960X

ISSN : 1961-960X

Éditeur :

CNRS (UMR 7528 Mondes iraniens et indiens), Éditions de l'IFRI

\section{Référence électronique}

Rémy Boucharlat, «Reza Naseri, Mehrdad Malekzadeh, Ali Naseri. "Gūnespān: a late Iron Age site in the Median heartland" », Abstracta Iranica [En ligne], Volume 37-38-39 | 2018, document 91, mis en ligne le 30 décembre 2018, consulté le 02 octobre 2020. URL : http://journals.openedition.org/ abstractairanica/46807 ; DOI : https://doi.org/10.4000/abstractairanica.46807

Ce document a été généré automatiquement le 2 octobre 2020.

Tous droits réservés 


\title{
Reza Naseri, Mehrdad Malekzadeh, Ali Naseri. "Gūnespān: a late Iron Age site in the Median heartland"
}

\author{
Rémy Boucharlat
}

\section{RÉFÉRENCE}

Reza Naseri, Mehrdad Malekzadeh, Ali Naseri. “Gūnespān: a late Iron Age site in the Median heartland", IA 51, 2016, p. 13-139

1 Localisé à $30 \mathrm{~km}$ au SE de Malayer, province de Hamadan, le site a fait l'objet de six campagnes de fouilles jusqu'en 2008, avant d'être noyé sous les eaux d'un barrage. Les travaux ont mis au jour un bâtiment, incomplet, de cinq pièces parallèles étroites (environ 3 à $3,60 \mathrm{~m})$ très longues $(21 \mathrm{~m})$, terminé sur l'un des petits côtés par un épais mur courbe appartenant à une phase postérieure, que les A comparent au mur extérieur courbe de Nush-i Jan ou celui du bâtiment de Tepe Ozbaki, tous deux datés de d'époque mède. Les A. comparent les phases architecturales de Gūnespān à celles de Godin Tepe II. Cette construction, qui n'a pas été remplie comme celle de Zar Bolagh, mais a été apparemment abandonnée, pose comme la plupart des constructions dites mèdes le problème de la date d'abandon puisque le qualificatif de mède n'est pas défini en termes de chronologie dans les rapports et articles sur les monuments découverts depuis les années 1980. 


\section{AUTEURS}

RÉMY BOUCHARLAT

UMR 5133 CNRS-Université de Lyon 